\title{
Measuring Efficiencies of Higher Education Using DEA
}

\author{
Min Hee Kim¹ ${ }^{1}$, Inhoi Lee ${ }^{2 *}$ and Sehee $\mathrm{Oh}^{3}$ \\ ${ }^{1}$ Department of Education, Graduate School of Education, Daegu University, \\ 201 Daegudaero, Gyeongsan-city, Gyeongdanbuk-Do, 712-714 South Korea \\ ${ }^{2}$ Department of Education, Graduate School of Education, Jeju National \\ University \\ 102 Jejudaehakro, Jeju-city, Jeju Special Self-Governing Province, 690-756 South \\ Korea \\ ${ }^{3}$ Department of Public Administration, College of Social Science, Inje University, \\ 197 Injero, Gimhae-city, Gyeongsangnam-Do, 621-749, South Korea \\ 1'minhee1016@daegu.ac.kr, ${ }^{2}$ tomlee816@hanmail.net, ${ }^{3}$ shoh@inje.ac.kr
}

\begin{abstract}
This study aimed to examine and compare internationally the relative efficiency of higher education by using data envelopment analysis (DEA). DEA is a non-parametric technique and known as a tool for measuring and analyzing the relative efficiency of nonprofit organizations. For this study, the contraction model was established with three input variables and three output variables. Output maximization was used to analyze the model. Presupposing variable return to scale, the DEA efficiency value of twelve OECD countries was evaluated. Testing the number of reference set for each country, the efficient country was identified. Evaluating the potential improvement-possibility value, the inefficient factor was also investigated. The efficiency scores of each country appeared very different.
\end{abstract}

Keywords: Data envelopment analysis, Efficiency, Input minimization, Output maximization

\section{Introduction}

Higher education is in a time of change, driven by technology, globalization, changing finances and public criticism. At the same time, higher education plays an increasingly crucial role in reinforcing knowledge-based society but also in strengthening a nation's competiveness by creating national wealth. Since the advantage of the great economic powers came from higher education sectors, each government of leading countries are now seeking implementation of higher education reform [1-2].

Efficiency is one of the most important variables that an individual university consistently pursues as an ultimate goal. There are two kinds of efficiencies: technical efficiency and allocative efficiency. Technical efficiency known as managerial efficiency is related to improving the methods of production and increasing the levels of output compared with inputs. Thus, it is inherently defined as the ratio of outputs to inputs. However, allocative efficiency is related to optimally allocating resources to the production of goods and services that consumers desire under the pressures of competition [3]. Over the last 20 years, there have been various attempts to construct performance indicators for universities using a variety of approaches. One of the attempts was to construct performance indicators relying on university-level data and hence using

\footnotetext{
${ }^{1}$ The first author

*Corresponding Author
} 
non-parametric method such as data envelopment analysis (DEA) to construct the efficiency measures [4].

DEA is a non-parametric technique which uses linear programming methods to estimate a piecewise linear frontier around the data against which the efficiency of each decision-making unit (DMU) can be measured. DEA can easily accommodate multiple inputs and multiple outputs, taking up advantage in the higher education context where the university is known to produce teaching and research outputs. This approach makes it possible to measure the degree of variation in efficiency across the university sector as a whole, and to identify possible sources of inefficiency. DEA constructs an 'efficiency frontier' with the most efficient organizations within a group being used to define the standard against which the performance of the other organizations is evaluated. Therefore, the concept of efficiency is relative rather than absolute [5-6]. However, DEA can be criticized for their use of aggregated data which do not allow for variation of within-unit relationships and the residuals of regression-based models will vary depending on the predictors included in the model [7]. Despite these downsides, DEA has frequently been applied in the higher education context.

There are two ways to measure relative efficiency in terms of mathematical programming: input-oriented model and output-oriented model. The input-oriented model concerns input minimization with maintaining the levels of outputs, whereas the outputoriented model focuses on output maximization in the same condition of inputs [8]. Since the CCR model in DEA formerly developed by Charnes, Cooper and Rhodes, various models have been developed. In the CCR model, efficiency is defined as a weighted sum of outputs to a weighted sum of inputs, where the weights structure is calculated by means of mathematical programming and constant returns to scale (CRS) are assumed [9]. The BCC model measures technical efficiency as the convexity constraint ensures that the composite unit is of similar scale size as the unit being measured. The resulting efficiency is always at least equal to the one given by the CCR model, and those DMUs with the lowest input or highest output levels are rated efficient [10]. Unlike the CCR model, the BCC model allows for variable returns to scale.

This study aimed to measure and compare internationally the relative efficiency of higher education by using the BCC model in DEA, and to find implications for improvement of its efficiency scores.

\section{Methodology}

\subsection{Input Variables}

In this study, the following input variables were used in the DEA analysis: ratio of students to teaching staff in educational institutions (Ratio of Students); expenditure on educational institutions as a percentage of GDP (Expenditure); and percentage of GERD performed by the higher education sector (Percentage of GERD).

\subsection{Output Variables}

It seems reasonable to argue that a university's output should be defined according to the services such as teaching, research, consultancy and other educational services it provides. The following core output variables were used in the DEA analysis: population that has attained tertiary education (PTE); university educational satisfaction (UES); and professor SCI per article number (Prof. SCI).

\subsection{Research Model}

For this study, the contraction model was employed as the methodology because the proper number of variables is twice of the total DMUs [8]. The research model with three 
input variables and three output variables is illustrated in Figure 1. In particular, the data of the given year of 2000 and 2002 was compared to the data of the year of 2012 and 2014 in order to measure the changes of higher education efficiency.

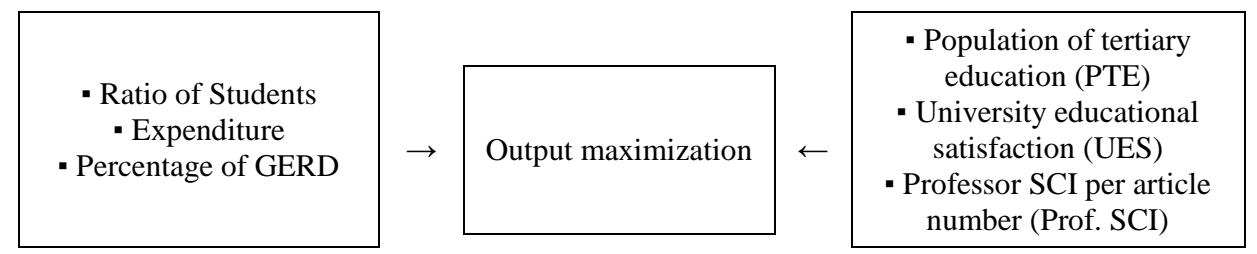

Figure 1. Research Frame with the Contraction Model

\subsection{Data Collection and Analysis}

In conducting this study, several sources of data were used. The major source was 'Education at a Glance' and its DB run by OECD. The total number of universities from tertiary type A and type B were included for the study. The second source involved using data from the statistical publications of higher education published by Korea, America, and United Kingdom. Data collected for 2002 and 2004 are similar to data collected in 2012 and 2014.

The Frontier Analyst 3.2 software, Excel 2002 and SPSS for Windows were used to analyze the DEA efficiency scores of twelve nations: America, Czech Republic, France, Germany, Hungary, Italy, Korea, Mexico, Poland, Spain, Sweden and UK. The DEA efficiency scores were calculated by the BCC model assuming VRS (variable Return to Scale). Also, measurement errors, as well as random influences on a university's output, were ignored [11].

\section{Results}

\subsection{Descriptive Statistics}

Descriptive statistics of the variables are presented in Table 1. As shown in Table 1, the results of all variables, ratio of students to teaching staff in educational institutions (Ratio of Students); expenditure on educational institutions as a percentage of GDP (Expenditure); and percentage of GERD performed by the higher education sector (Percentage of GERD); population that has attained tertiary education (PTE); university educational satisfaction (UES) and professor SCI per article number (Prof. SCI), have been rising consistently.

Table 1. Descriptive Statistics

\begin{tabular}{cccccccccccccc}
\hline & \multicolumn{3}{c}{2000} & \multicolumn{3}{c}{2002} & & 2012 & & \multicolumn{2}{c}{2014} \\
\cline { 2 - 12 } Variables & $\mathrm{M}$ & $\mathrm{SE}$ & $\mathrm{OECD}$ & $\mathrm{M}$ & $\mathrm{SE}$ & $\mathrm{OECD}$ & $\mathrm{M}$ & $\mathrm{SE}$ & OECD & $\mathrm{M}$ & SE & OECD \\
\hline \hline Ratio of Students & 6.9 & 2.7 & 6.8 & 6.5 & 2.5 & 3.6 & 14.3 & 3.5 & 15.5 & 14.6 & 4.7 & 14.0 \\
\hline Expenditure & 0.9 & 0.2 & 0.9 & 0.9 & 0.3 & 0.9 & 1.0 & 0.3 & 1.1 & 1.0 & 0.2 & 1.1 \\
\hline Percentage of GERD & 0.04 & 0.02 & 0.04 & 0.04 & 0.02 & 0.08 & 23.4 & 7.4 & 18.36 & 23.4 & 7.0 & 18.4 \\
\hline PTE & 25.6 & 11.6 & 26.0 & 27.5 & 12.6 & 28.0 & 29.0 & 9.5 & 31.0 & 29.4 & 9.7 & 32.0 \\
\hline UES & 5.4 & 1.2 & 5.8 & 5.2 & 1.5 & 5.9 & 5.5 & 1.0 & 6.06 & 5.7 & 1.2 & 6.1 \\
\hline Prof. SCI & 0.36 & 0.2 & 0.32 & 0.35 & 0.2 & 0.5 & 0.34 & 0.1 & 0.37 & 0.3 & 0.1 & 0.4 \\
\hline
\end{tabular}

In comparing the twelve nations to OECD, it can be seen that the statistics are 
generally a little lower than that of OECD average in the four variables besides the two variables of Expenditure and Percentage of GERD. This means that these nations have increased inputs related to teaching for students and researches of professors in the higher education context.

\subsection{Comparisons of the Efficiency Scores}

The results from the comparison of the DEA efficiency scores under the condition of output maximization are displayed in Table 2. Note that the table reports the efficiency levels relative to their individual country. That is, the scores are relative scores. The efficiency scores of four nations (America, Spain, UK, and Korea) show an identical percentage of $100 \%$. For Germany and Sweden, the efficiency scores have increased, while Mexico, Czech Republic and Hungary have performed the lower efficiency scores, in comparison to the given year 2002 and 2002 to the year 2012 and 2014. Especially, the efficiency score of Mexico is the lowest (68.90\%). The number of nations that are inefficient in the scores was five in the given year 2002, reduced to four in the year 2004; and increased to six in the compared year of 2012 and 2014.

Table 2. Comparison of DEA Efficiency Scores

\begin{tabular}{ccccc}
\hline DMU & 2000 & 2002 & 2012 & 2014 \\
\hline \hline Germany & 83.03 & 78.05 & 100.0 & 100.0 \\
\hline Mexico & 100.0 & 100.0 & 65.07 & 68.90 \\
\hline America & 100.0 & 100.0 & 100.0 & 100.0 \\
\hline Sweden & 98.93 & 100.0 & 100.0 & 100.0 \\
\hline Spain & 100.0 & 100.0 & 100.0 & 100.0 \\
\hline UK & 100.0 & 100.0 & 100.0 & 100.0 \\
\hline Italy & 100.0 & 96.30 & 100.0 & 100.0 \\
\hline Czech Republic & 100.0 & 100.0 & 91.35 & 74.86 \\
\hline Poland & 96.93 & 100.0 & 82.86 & 85.90 \\
\hline France & 95.25 & 93.51 & 76.70 & 82.37 \\
\hline Hungary & 100.0 & 100.0 & 76.41 & 70.12 \\
\hline Korea & 100.0 & 100.0 & 100.0 & 100.0 \\
\hline Average & 97.85 & 97.32 & 91.03 & 90.18 \\
\hline $\begin{array}{c}\text { Number of inefficient } \\
\text { countries }\end{array}$ & 5 & 4 & 6 & 6 \\
(Less than 100\%) & & & & \\
\hline & & & 6
\end{tabular}

\subsection{Test of Reference Set}

The results analyzing the efficient reference set are presented in Table 3 . The test is to count the number of times efficient units appear on the efficient reference set for inefficient units. As shown in Table 3, America appears in the most efficient reference for inefficient countries three times in 2000, five times in 2012 and 2014. Sweden appears between one and five times. UK and Korea appear to be efficient for a total of eight times each. For Korea, the result of the test is high in the efficient reference, which means that it is really efficient and operates at best in practice, making efforts for the efficiency of higher education. 
Table 3. Comparison of the Efficient Reference Set

\begin{tabular}{|c|c|c|c|c|c|}
\hline$\overline{\mathrm{DMU}}$ & 2000 & 2002 & 2012 & 2014 & Total \\
\hline Germany & & & 2 & 4 & 6 \\
\hline Mexico & 1 & & & & 1 \\
\hline America & 3 & & 5 & 5 & 13 \\
\hline Sweden & & 1 & 5 & 4 & 10 \\
\hline Spain & 1 & & & & 1 \\
\hline UK & 2 & 2 & 4 & & 8 \\
\hline Italy & & & 2 & 4 & 6 \\
\hline Czech Republic & 1 & 1 & & & 2 \\
\hline Poland & & & & & 0 \\
\hline France & & & & & 0 \\
\hline Hungary & 1 & & & & 1 \\
\hline Korea & 2 & & 3 & 3 & 8 \\
\hline
\end{tabular}

\subsection{Analysis of Inefficient Variables}

Table 4 demonstrates the scores of inefficient output variables in 2012 and 2014. As seen in Table 4, Mexico, Czech Republic, Poland and France should increase the levels of all the variables, PTE, UES and Prof. SCI, in order to improve the inefficiency scores of higher education. Especially, Czech Republic is in the lowest level (16.1\% in 2014) in the variable of PTE, and Mexico is in the lowest inefficiency scores of UES and Prof. SCI variables.

Table 4. Inefficient Output Variables

\begin{tabular}{ccccccc}
\hline \multirow{2}{*}{ DMU } & \multicolumn{3}{c}{2012} & & \multicolumn{3}{c}{2014} \\
\cline { 2 - 7 } & PTE & UES & Prof. SCI & PTE & UES & Prof. SCI \\
\hline \hline Germany & 0.0 & 0.0 & 0.0 & 0.0 & 0.0 & 0.0 \\
\hline Mexico & 16.088 & 2.319 & 0.12 & 13.825 & 2.054 & 0.116 \\
\hline America & 0.0 & 0.0 & 0.0 & 0.0 & 0.0 & 0.0 \\
\hline Sweden & 0.0 & 0.0 & 0.0 & 0.0 & 0.0 & 0.0 \\
\hline Spain & 0.0 & 0.0 & 0.0 & 0.0 & 0.0 & 0.0 \\
\hline UK & 0.0 & 0.0 & 0.0 & 0.0 & 0.0 & 0.0 \\
\hline Italy & 0.0 & 0.0 & 0.0 & 0.0 & 0.0 & 0.0 \\
\hline Czech Republic & 16.516 & 1.392 & 0.03 & 16.063 & 1.672 & 0.109 \\
\hline Poland & 13.736 & 1.123 & 0.067 & 4.102 & 0.914 & 0.057 \\
\hline France & 8.807 & 1.626 & 0.083 & 6.635 & 1.305 & 0.061 \\
\hline Korea & 0.0 & 0.0 & 0.0 & 0.0 & 0.0 & 0.0 \\
\hline Hungary & 7.416 & 1.55 & 0.08 & 10.315 & 2.01 & 0.113 \\
\hline
\end{tabular}

\section{Conclusions}

This study aimed to examine and compare the efficiency of higher education using 
DEA with twelve OECD nations. The conclusions drawn from the study are as follows.

First, there were differences of the DEA efficiency scores in accordance to both the given year and the variables. Four countries (America, Spain, UK, and Korea) had performed $100 \%$ in the efficiency scores regardless of the given years, while the efficiency scores of three countries (Mexico, Czech Republic, and Hungary) had been decreasing. The results of this study indicate that there exists large deviation of the efficiency of higher education among the twelve OECD nations. It is quite suggestive that the strategies improving the level of output should be developed based on input considering the limit of financial resources of each nation.

Second, the results of this study showed that Korea had maintained a $100 \%$ of the efficiency of higher education. It means that Korea is the nation which has maximized relative output variables such as PTE, UES and Prof. SCI under the inputs of Ratio of Students, Expenditure, Percentage of GERD, and is the nation which is highly efficient by maintaining the efficiency scores. However, high efficiency does not mean high competitiveness of higher education. Therefore, qualitative substantialization is to be needed rather than quantitative expansion of higher education.

Third, as results of testing the efficient reference set, America, Sweden and Korea appeared to be efficient out of twelve countries. However, caution should be exercised in that the scores are not absolute, because the scores are restricted by the used DEA variables. Nevertheless, Sweden and Korea have been demonstrating their efficiency in the given years. It suggests that the two countries have made efforts for output maximization even in the condition of the same inputs.

Fourth, in searching for the inefficient variables in order to discover potential improvements, the results showed that the nations which were inefficient in the context of higher education should improve the output variables. In the case of the nations that were inefficient in the variables of PTE and UES, these nations should find the concrete inefficient factors from the inside of universities and make efforts to improve them in times of a nation's competitiveness.

Lastly, this study compared the efficiency of higher education among twelve OECD nations with the four given years $(2000,2002 ; 2012,2014)$. As results, the eight nations' deviation of the DEA efficiency scores (besides America, Spain, UK, and Korea) is high. This implies that these kinds of findings are crucial to expand opportunities of higher education, and establish the direction of sustainable development with strategic investment in the higher education context.

\section{References}

[1] H. S. Shin, H. Chu and B. Kim, "Higher Education Reform in U.S., U.K. and Japan: A Comparative Analysis", The Korea Educational Review, vol. 19, no. 2, (2013), pp. 249-279.

[2] M. Abbott and C. Doucouliagos, "The Efficiency of Australian Universities: A Data Envelopment Analysis", Economics of Education Review, vol. 22, no. 1, (2002), pp. 89-97.

[3] M. Abbott and C. Doucouliagos, "Competition and Efficiency: Overseas Student and Technical Efficiency in Australian and New Zealand Universities", Education Economics, vol. 17, no. 1, (2009), pp. 31-57.

[4] J. Johnes, "Measuring Efficiency: A Comparison of Multilevel Modeling and Data Envelopment Analysis in the Context of Higher Education", Bulletin of Economic Research, vol. 58, no. 2, (2006), pp. 3370-3378.

[5] A. T. Flegg, D.O. Allen and K. Field, "Thurlow, T.W.: Measuring the Efficiency of British Universities: A Multi-period Data Envelopment Analysis", Education Economic, vol. 12, no. 3, (2004), pp. 231-249.

[6] S. Jeon and S. Kim, "Analysis of the Productivity Changes in Government-funded Research Institute for Economies \& Humanities and Social Sciences", Journal of the Korea Academia-Industrial Cooperation Society, vol. 15, no. 10, (2014), pp. 6066-6075.

[7] G. Woodhouse and H. Goldstein, "Educational Performance Indicators and LEA League Tables", Oxford Review of Education, vol. 14, (1988), pp. 301-319.

[8] Banxia Software: Banxia Frontier Analyst User's Guide. Banxia Software Limited, UK, (2003)

[9] A Charnes, W.W. Cooper and E. Rhodes, "Measuring the Efficiency of Decision Making Units", European Journal of Operational Research, vol. 2, (1978), pp. 429-44. 
[10] R. D. Banker, A. Charnes and W. W. Cooper, "Some Models for Estimating Technical and Scale Inefficiencies in Data Envelopment Analysis", Management Science, vol. 30, no. 9, (1984), pp. 10781092.

[11] M. H. Park, "Efficiency and Productivity Analysis. Korean Studies Information, Seoul, (2008) 
International Journal of $u-$ and e- Service, Science and Technology Vol.9, No. 5 (2016) 